\title{
Brain acetylcholinesterase activity in mild cognitive impairment and early Alzheimer's disease
}

\author{
J O Rinne, V Kaasinen, T Järvenpää, K Någren, A Roivainen, M Yu, V Oikonen, T Kurki
}

J Neurol Neurosurg Psychiatry 2003;74:113-115

Objective: Brain acetylcholinesterase activity was determined in healthy controls and in patients with mild cognitive impairment and early Alzheimer's disease.

Methods: A specific acetylcholinesterase tracer, [methyl$\left.{ }^{1} \mathrm{C}\right] \mathrm{N}$-methyl-piperidyl-4-acetate ([ $\left.\left.{ }^{\prime} \mathrm{C}\right] \mathrm{MP} 4 \mathrm{~A}\right)$, and a three dimensional PET system with magnetic resonance coregistration were used for imaging.

Results: There was a significant difference in the acetylcholinesterase activity in the hippocampus between the groups ( $p=0.03$ ), the mean (SD) acetylcholinesterase activity $\left(k_{3}\right.$ values, $\left.\mathrm{min}^{-1}\right)$ being $0.114(0.036)$ in controls, $0.098(0.023)$ in mild cognitive impairment, and 0.085 (0.022) in Alzheimer's disease. The mini-mental state examination score showed no significant relation with acetylcholinesterase activity in any brain area in the combined mild cognitive impairment/Alzheimer group.

Conclusions: Hippocampal acetylcholinesterase activity is only slightly reduced in mild cognitive impairment and early Alzheimer's disease and so the value of in vivo acetylcholinesterase measurements in detecting the early Alzheimer process is limited.

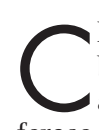
holinergic deficiency is the most severe and consistent biochemical change in Alzheimer's disease. This is seen as reduced levels of acetylcholine, choline acetyltransferase, and acetylcholinesterase, ${ }^{12}$ reported in both necropsy brain samples and in cerebrospinal fluid. Only recently has it been possible to measure the acetylcholinesterase activity directly in the brain in vivo.

With positron emission tomography (PET), cortical acetylcholinesterase activity has been evaluated by piperidyl derivatives such as $N-\left[{ }^{11} \mathrm{C}\right]$ methylpiperidyl-4-propionate $\left(\left[{ }^{11} \mathrm{C}\right] \mathrm{MP} 4 \mathrm{P}\right.$ or $\left.\quad\left[{ }^{11} \mathrm{C}\right] \mathrm{PMP}\right)^{3}$ and $N-\left[{ }^{11} \mathrm{C}\right]$ methylpiperidyl-4-acetate $\left(\left[{ }^{11} \mathrm{C}\right] \mathrm{MP} 4 \mathrm{~A}\right) .^{4-7}$ In these studies, the cortical cholinergic activity in Alzheimer's disease has been reported to decline by $16-45 \%$ compared with healthy controls.

Mild cognitive impairment is a transitional stage between normal aging and early Alzheimer's disease. ${ }^{89}$ Individuals with mild cognitive impairment have memory impairment by definition, but their general cognitive function is normal and activities of daily living are intact. Volumetric magnetic resonance imaging (MRI) has shown that the entorhinal cortex and hippocampal volumes are reduced in mild cognitive impairment, ${ }^{10}$ and that there is loss of entorhinal cortex neurones. ${ }^{11}$ In PET studies, reduction of glucose metabolism in the hippocampal formation has been seen without any significant neocortical change. ${ }^{12}$ Imaging results therefore indicate that at a structural and metabolic level the first pathological changes develop in the entorhinal and hippocampal areas. However, little is known about the cholinergic system in mild cognitive impairment.

We were interested to determine whether changes in the cholinergic system in the temporal regions could be detected in the early phases of the Alzheimer process. We therefore undertook $\left[{ }^{11} \mathrm{C}\right] \mathrm{MP} 4 \mathrm{~A}$ PET studies in healthy controls and in patients with mild cognitive impairment and early Alzheimer's disease.

\section{METHODS \\ Patients}

We studied 13 patients with Alzheimer's disease (eight women and five men; mean (SD) age, 68.8 (9.0) years) who fulfilled the NINCDS-ADRDA criteria for probable Alzheimer's disease. All patients underwent a full clinical neurological investigation, laboratory tests, neuropsychological investigation, and brain 1.5 T MRI. The neuropsychological investigation consisted of tests assessing attention, memory, language, psychomotor functions, and visuospatial and visuoconstructive abilities. In addition, the mini-mental state examination (MMSE) was carried out. Mean (SD) MMSE scores were 20.4 (5.5), range 16 to 25 . The clinical dementia rating was 1.0 in all patients, indicating that they all had mild Alzheimer's disease. The onset of the disease was below 65 years of age in four patients.

The patients with mild cognitive impairment ( $n=12$, seven women and five men; mean (SD) age, 64.8 (8.8) years) had subjective memory complaints and showed an impairment greater than $1.5 \mathrm{SD}$ from the mean of healthy controls in at least one memory test. ${ }^{89}$ The MMSE score was equal to or greater than 25 in all cases, the mean (SD) MMSE score being 26.0 (1.1), range 25 to 28. The CDR score for all subjects with mild cognitive impairment was 0.5 . The subjects with mild cognitive impairment underwent the same investigations as the Alzheimer group.

In addition, we studied 12 healthy elderly volunteers as controls (seven women and five men; mean (SD) age, 64.8 (6.5) years) who had no history of neurological or psychiatric disorders. These were mainly spouses of the subjects with Alzheimer's disease and mild cognitive impairment and had no family history of Alzheimer's disease.

All participants gave their written informed consent. The study was approved by the joint ethics committee of Turku University and Turku University Central Hospital.

\section{Radiochemistry}

$\left[{ }^{11} \mathrm{C}\right] \mathrm{MP} 4 \mathrm{~A}$ was produced by the reaction of 4 -acetylpiperidine, generated in situ from its hydrochloride salt using 2,2,6,6,N-pentamethyl-piperidine (PMP) and $\left[{ }^{11} \mathrm{C}\right]$ methyl triflate in methanol/acetonitrile for one minute at $60^{\circ} \mathrm{C}$. Details of the method have been published previously. ${ }^{13}$ The radiochemical purity of the product was greater than $99 \%$, and the specific radioactivity greater than $37 \mathrm{MBq} / \mathrm{hmol}$.

\section{PET imaging}

The PET imaging was undertaken with a GE Advance PET scanner (General Electric Medical Systems, Milwaukee, Wisconsin, USA) in the three dimensional scanning mode, as described earlier. ${ }^{13}$ The injected doses of radioactivities were 515 (119) MBq for Alzheimer's disease, 538 (85) MBq for mild cognitive impairment, and 526 (77) $\mathrm{MBq}$ for controls. $\left[{ }^{11} \mathrm{C}\right] \mathrm{MP} 4 \mathrm{~A}$ was injected intravenously as a bolus during 80 seconds, and a dynamic 60 minute study was performed. 
Table $1 \mathrm{k}_{3}$ Values of [ $\left.{ }^{11} \mathrm{C}\right] \mathrm{MP} 4 \mathrm{~A}$ in healthy controls and in patients with mild cognitive impairment and Alzheimer's disease

\begin{tabular}{|c|c|c|c|c|}
\hline Region & Control & $\mathrm{MCl}$ & $A D$ & p Value* \\
\hline $\begin{array}{l}\text { Hippocampus } \\
\% \text { of control mean }\end{array}$ & $0.114(0.036)$ & $\begin{array}{l}0.095(0.026) \\
83 \%\end{array}$ & $\begin{array}{l}0.084(0.018) \\
73 \%\end{array}$ & 0.03 \\
\hline $\begin{array}{l}\text { Frontal cortex } \\
\% \text { of control mean }\end{array}$ & $0.074(0.014)$ & $\begin{array}{l}0.071(0.020) \\
95 \%\end{array}$ & $\begin{array}{l}0.068(0.011) \\
91 \%\end{array}$ & 0.59 \\
\hline $\begin{array}{l}\text { Temporal cortex } \\
\% \text { of control mean }\end{array}$ & $0.075(0.011)$ & $\begin{array}{l}0.067(0.022) \\
90 \%\end{array}$ & $\begin{array}{l}0.060(0.010) \\
80 \%\end{array}$ & 0.06 \\
\hline $\begin{array}{l}\text { Parietal cortex } \\
\% \text { of control mean }\end{array}$ & $0.075(0.026)$ & $\begin{array}{l}0.069(0.019) \\
92 \%\end{array}$ & $\begin{array}{l}0.058(0.015) \\
77 \%\end{array}$ & 0.11 \\
\hline $\begin{array}{l}\text { Thalamus } \\
\% \text { of control mean }\end{array}$ & $0.167(0.058)$ & $\begin{array}{l}0.186(0.073) \\
111 \%\end{array}$ & $\begin{array}{l}0.164(0.078) \\
98 \%\end{array}$ & 0.70 \\
\hline
\end{tabular}

To obtain the input function, arterial radioactivity concentrations were measured. For the metabolite analysis, the amount of unchanged $\left[{ }^{11} \mathrm{C}\right] \mathrm{MP} 4 \mathrm{~A}$ in arterial plasma was determined using high performance liquid chromatography.

\section{Regions of interest}

For anatomical reference and to exclude structural lesions, each individual was scanned with MRI. MRI scans were acquired with a $1.5 \mathrm{~T}$ Siemens Magnetom system (Erlangen, Germany) using a standard head coil. A sagittal three dimensional MPR sequence (magnetisation prepared rapid gradient echo; time of repetition 10, time of echo 4, flip angle $10^{\circ}$, matrix $192 \times 256$, contiguous $1.5 \mathrm{~mm}$ slices, one acquisition) was obtained in all cases. For evaluation of hippocampal atrophy, oblique coronal $3 \mathrm{~mm}$ thick slices oriented perpendicularly to the long axis of hippocampus were reconstructed.

PET and MRI planes were realigned with a surface fit computer program ${ }^{14}$ so that the planes corresponded in the axial and transaxial position. After realignment, regions of interest (ROIs) were drawn on magnetic resonance (MR) images and transferred to the corresponding planes in the PET images. ROIs were delineated to the prefrontal cortex (areas 9 and 10 in five planes), the parietal cortex (in three planes), the lateral temporal cortex (in four planes), and the hippocampus (in two planes) in the medial temporal lobe in each hemisphere. The rate constants $\left(\mathrm{k}_{3}\right)$ for hydrolysis of $\left[{ }^{11} \mathrm{C}\right] \mathrm{MP} 4 \mathrm{~A}$ were estimated using a mathematical model described previously, ${ }^{4}{ }^{15}$ with the metabolite corrected arterial plasma activity as the input function.

\section{Evaluation of hippocampal atrophy}

Possible hippocampal atrophy was evaluated visually by an experienced neuroradiologist (TK), and scored from no atrophy (0) to severe atrophy (4) using a five point scale. ${ }^{16}$ The left hippocampus and the right hippocampus were evaluated separately.

\section{Statistics}

The statistical computations were performed with the SAS System for Windows, release 8.00 (SAS Inc, Cary, North Carolina, USA). As there were no significant side to side differences in the $\mathrm{k}_{3}$ values, average left and right hemisphere values were used for the statistical analysis. One way analysis of variance (ANOVA) was done to compare $\mathrm{k}_{3}$ values between the subject groups. When ANOVA revealed differences between subject groups, individual group means were compared with each other using Student's $t$ test with Bonferroni correction for multiple comparisons. Pearson's correlation coefficient was used to test the association between the $\mathrm{k}_{3}$ values and MMSE scores of the patients. The semiquantitative hippocampal volumes were compared between the groups using KruskallWallis ANOVA. Probability (p) values of $\leqslant 0.05$ were interpreted as statistically significant.

\section{RESULTS}

One way ANOVA showed that there was a significant difference in acetylcholinesterase activity between the subject groups only in the hippocampus $(p=0.03)$. In Alzheimer's disease, the mean acetylcholinesterase activity in the hippocampus was reduced by $27 \%$ from the control mean $(p=0.04$ after Bonferroni correction for multiple comparisons). The reductions in other brain areas varied between $2 \%$ and $23 \%$. In mild cognitive impairment, the hippocampal $\mathrm{k}_{3}$ for $\left[{ }^{11} \mathrm{C}\right] \mathrm{MP} 4 \mathrm{~A}$ was reduced by $17 \%$ from the control mean. In other brain areas, the acetylcholinesterase activity was at control level. The absolute $\mathrm{k}_{3}$ values are given in table $\mathrm{l}$, and the percentage reductions from control mean are shown in fig 1 .

The hippocampal volume both in the left and the right hemisphere was significantly different between the groups $(\mathrm{p}<0.001$, Kruskall-Wallis ANOVA). The patients with Alzheimer's disease had, as could be expected, the highest atrophy scores: $2.4(0.8)$ for Alzheimer's disease, $1.4(0.8)$ for mild cognitive impairment, and 0.5 (0.7) for controls in the right hippocampus; and $2.5(0.9), 1.5(0.8)$, and $0.5(0.7)$, respectively, in the left hippocampus). The volumes $\left(\mathrm{mm}^{3}\right)$ of the ROIs in PET were, however, not significantly different between the groups ( $p=0.75$ for left hippocampus; $p=0.94$ for right hippocampus, ANOVA).

There was no significant correlation between the MMSE scores and acetylcholinesterase activity in the combined mild cognitive impairment/Alzheimer group ( $r$ ranging from -0.08 to $0.18, \mathrm{p}>0.41$ in all correlations).

\section{DISCUSSION}

Our results show that there is a slight reduction in acetylcholinesterase activity in the hippocampus in patients with early

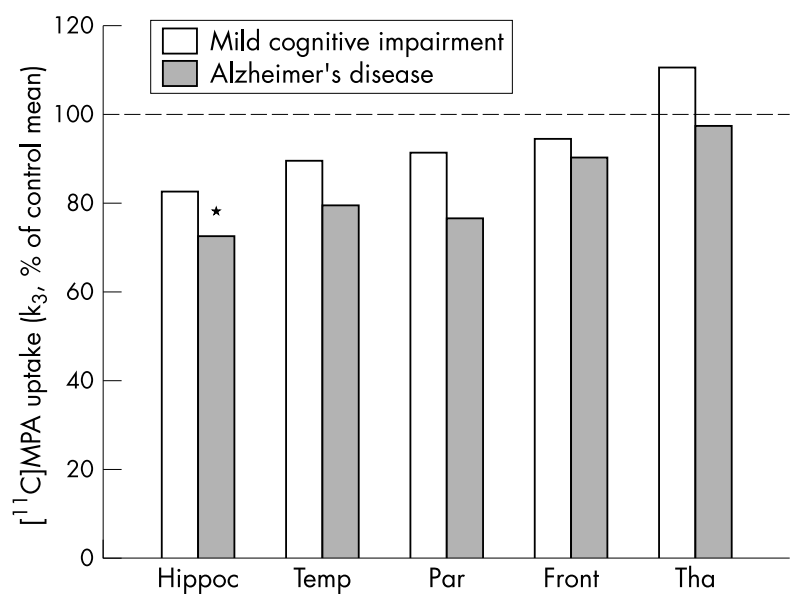

Figure 1 The percentage reduction from control mean (dashed line) in hippocampal, frontal, temporal, parietal, and thalamic acetylcholinesterase (AChE) activities ( $k_{3}$ values) in patients with mild cognitive impairment (MCI) and Alzheimer's disease (AD).

${ }^{*} p<0.05 v$ controls. Front, frontal cortex; Hippoc, hippocampus; Par, parietal cortex; Temp, temporal cortex; Tha, thalamus. 
Alzheimer's disease. In mild cognitive impairment the mean hippocampal acetylcholinesterase activity was less than in controls, but the difference was not statistically significant.

The mean acetylcholinesterase activity was reduced by $27 \%$ in the hippocampus in Alzheimer's disease, and by $20 \%$ in the lateral temporal cortex and $23 \%$ in the parietal cortex, but was at mean control level in the frontal cortex and thalamus. In previous studies, more severe and widespread reductions in acetylcholinesterase activity have been reported, ${ }^{3{ }^{467}}$ but the reduction was most severe in the parietotemporal cortex, ${ }^{3}$ where reductions were also seen in the present study. In the previous studies, the patients have, however, been more severely demented-judging by the mean MMSE scores $\left(14,{ }^{4}\right.$ $17.6^{6}$ ) - than the patients in the present study (mean MMSE score 20.4). Accordingly, in necropsy brain tissue, cortical acetylcholinesterase activity did not differ significantly between subjects with CDR scores of 0.0 to 2.0 , but was significantly different in subjects with severe dementia (CDR scores 4.05.0). ${ }^{17}$ It may be that in early Alzheimer's disease and mild cognitive impairment there is relative upregulation or compensation of acetylcholinesterase, as has recently been reported for choline acetyltransferase ${ }^{18}$ However, at least in the present study acetylcholinesterase levels did not exceed that seen in controls (except for the thalamus) in either Alzheimer's disease or mild cognitive impairment.

To our knowledge, this is the first study to investigate in vivo acetylcholinesterase activity in patients with mild cognitive impairment. This condition is a risk stage for developing Alzheimer's disease, and the rate of conversion to dementia (usually to Alzheimer's disease) has varied between 6\% and $25 \%$, being usually around $12-15 \%$ annually. ${ }^{9}$ Thus a considerable number of people with mild cognitive impairment may have early Alzheimer's disease changes in the brain. We saw a $17 \%$ reduction in mean hippocampal acetylcholinesterase activity in mild cognitive impairment, whereas the activity in all other brain areas was between $90 \%$ to $111 \%$ of the control mean. This is compatible with the pathology being concentrated in the entorhinal cortex and the hippocampus in mild cognitive impairment. In addition, nucleus basalis cholinergic neurones projecting to cortical areas are preserved in mild cognitive impairment, ${ }^{19}$ indicating that neocortical cholinergic activity is relatively intact in this condition.

The entorhinal cortex and hippocampus show atrophy and neuronal loss in both mild cognitive impairment and Alzheimer's disease. ${ }^{10}{ }^{11}$ Also in the present study, hippocampal atrophy — estimated visually by a semiquantitative scale-was increased in both conditions compared with the healthy controls. An excellent correlation of this kind of visual evaluation with volumetric measurements has been shown. ${ }^{20}$ The reduced hippocampal volume together with reduced $\mathrm{k}_{3}$ for methylpiperidyl acetate raises the question of a partial volume effect. However, in the present study, the ROIs were drawn on MR images matched with the PET images, and the ROIs were thus determined by anatomical reference and not by the distribution of radioactivity concentration. The volume of the hippocampal ROIs was not different between the subject groups, indicating that the partial volume effect is unlikely to explain the present results. In previous studies, ${ }^{36}$ the ROIs were drawn without matching MR and PET images. Thus the partial volume effect might have enhanced the reductions reported. On the other hand, it was noted that atrophy had little influence on the measures of $\mathrm{k}_{3}$ decline in acetylcholinesterase activity. ${ }^{3}$

Acetylcholinesterase is located in both cholinergic and cholinoceptive (non-cholinergic) neurones. It has been noted that people with Alzheimer's disease may display an almost normal density of acetylcholinesterase-rich cholinoceptive perikarya in regions of the cortex that show severe loss of acetylcholinesterase-rich axons. ${ }^{21}$ Thus in early Alzheimer's disease, ligands reflecting acetylcholine synthesis could be more useful in the early diagnosis than those reflecting acetylcholinesterase activity.

\section{ACKNOWLEDGEMENTS}

We thank the staff of the Turku PET Centre for their help. The study was supported by the Turku University Central Hospital (EVO) and the Päivikki and Sakari Sohlberg Foundation.

\section{Authors' affiliations \\ J O Rinne, V Kaasinen, Department of Neurology, University of Turku, Finland \\ T Kurki, Department of Radiology, University of Turku \\ T Järvenpää, K Någren, A Roivainen, M Yu, V Oikonen, Turku PET \\ Centre, Turku}

Competing interests: none declared

Correspondence to: Dr Juha $O$ Rinne, Turku PET Centre, PO Box 52, FIN-20521, Turku, Finland; juha.rinne@pet.tyks.fi

Received 24 April 2002

In revised form 30 August 2002

Accepted 12 September 2002

\section{REFERENCES}

1 Perry EK, Perry RH, Blessed G, et al. Necropsy evidence of central cholinergic deficits in senile dementia. Lancet 1977;i:189.

2 Francis PT, Palmer AM, Snape M, et al. The cholinergic hypothesis of Alzheimer's disease: a review of progress. J Neurol Neurosurg Psychiatry 1999:66:137-47.

3 Kuhl DE, Koeppe RA, Minoshima S, et al. In vivo mapping of cerebral acetylcholinesterase activity in aging and Alzheimer's disease. Neurology 1999:52:691-9.

4 lyo $M$, Namba H, Fukushi K, et al. Measurement of acetylcholinesterase by positron emission tomography in the brains of healthy controls and patients with Alzheimer's disease. Lancet 1997;349:1805-9.

5 Shinotoh $\mathbf{H}$, Aotsuka A, Fukushi K, et al. Effect of donepezil on brain acetylcholinesterase activity in patients with $A D$ measured with PET. Neurology 2001;56:408-10.

6 Shinotoh H, Namba H, Fukushi K, et al. Progressive loss of cortical acetylcholinesterase activity in association with cognitive decline in Alzheimer's disease: a positron emission tomography study. Ann Neurol 2000:48:194-200.

7 Herholz K, Baver B, Wienhard K, et al. In-vivo measurement of regional acetylcholine esterase activity in degenerative dementia: comparison with blood flow and glucose metabolism. J Neural Transm 2000;107: 1457-68.

8 Petersen RC, Smith GE, Waring SC, et al. Mild cognitive impairment: clinical characterization and outcome. Arch Neurol 1999;56:303-8.

9 Petersen RC, Stevens JC, Ganguli M, et al. Practice parameter: early detection of dementia: mild cognitive impairment (an evidence based review). Neurology 2001;56:1133-42.

10 Du AT, Schuff N, Amend D, et al. Magnetic resonance imaging of the entorhinal cortex and hippocampus in mild cognitive impairment and Alzheimer's disease. J Neurol Neurosurg Psychiatry 2001;71:441-7.

11 Kordower JH, Chu Y, Stebbins GT, et al. Loss and atrophy of layer II entorhinal cortex neurons in elderly people with mild cognitive impairment. Ann Neurol 2001:49:202-13.

12 De Santi S, de Leon M, Rusinek H, et al. Hippocampal formation glucose metabolism and volume losses in $\mathrm{MCl}$ and $\mathrm{AD}$. Neurobiol Aging $2001 ; 22: 529-39$.

13 Kaasinen V, Någren K, Järvenpää T, et al. Regional effects of donepezil and rivastigmine on cortical acetylcholinesterase activity in Alzheimer's disease. J Clin Psychopharmacol (in press).

14 Pellizzari CA, Chen GTY, Spelbring DR, et al. Accurate three-dimensional registration of CT, PET, and/or MR images of the brain. J Comput Assist Tomogr 1989;13:20-6.

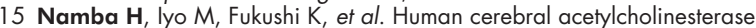
activity measured with positron emission tomography: procedure, normal values and effect of age. Eur J Nucl Med 1999;26:135-43.

16 Scheltens P, Leys D, Barkhof F, et al. Atrophy of medial temporal lobes on MRI in "probable" Alzheimer's disease and normal ageing: diagnostic value and neuropsychological correlates. J Neurol Neurosurg Psychiatry 1992;55:967-72.

17 Davis KL, Mohs RC, Marin D, et al. Cholinergic markers in elderly patients with early signs of Alzheimer's disease. JAMA 1999;281;1401-6.

18 DeKosky ST, Ikonomovic MD, Styren SD, et al. Upregulation of choline acetyltransferase activity in hippocampus and frontal cortex of elderly subjects with mild cognitive impairment. Ann Neurol 2001;51:145-55.

19 Gilmor ML, Erickson JD, Varoqui $\mathrm{H}$, et al. Preservation of nucleus basalis neurons containing choline acetyltransferase and the vesicular acetylcholine transporter in the elderly with mild cognitive impairment and early Alzheimer's disease. J Comp Neurol 1999:41 1:693-704.

20 Wahlund LO, Julin $P$, Johansson SE, et al. Visual rating and volumetry of the medial temporal lobe on magnetic resonance imaging in dementia: a comparative study. J Neurol Neurosurg Psychiatry 2000;69:630-5.

21 Mesulam M. Neuroanatomy of cholinesterases in the normal human brain and in Alzheimer's disease. In: Giacobini E, ed. Cholinesterases and cholinesterase inhibitors. London: Martin Dunitz, 2000:121-37. 